\title{
Microstructure Characteristics and Mechanical Properties of Nb- 17Si-23Ti Ternary Alloys Fabricated by In Situ Reaction Laser Melting Deposition
}

\author{
Wei Liu ${ }^{1} \cdot$ Hua-Ping Xiong ${ }^{1} \cdot{\text { Neng } \mathrm{Li}^{1} \cdot \text { Shao-Qing Guo }}^{1} \cdot$ Ren-Yao Qin ${ }^{1}$
}

Received: 12 April 2017/Revised: 30 May 2017/Published online: 6 July 2017

(C) The Chinese Society for Metals and Springer-Verlag GmbH Germany 2017

\begin{abstract}
Fabrication of ternary $\mathrm{Nb}-17 \mathrm{Si}-23 \mathrm{Ti}$ alloys was attempted by in situ reaction laser melting deposition (LMD) with dual powder feeding method from $\mathrm{Nb}-28$ at.\% Ti powder mixture and pure Si powder. The microstructures of the asdeposited alloys were examined with scanning electronic microscope, and the phase constituents were analyzed by X-ray energy-dispersive spectrometer and X-ray diffraction. Furthermore, the effect of laser power on microstructure characteristics, microhardness and indentation fracture toughness was also investigated. The in situ reaction LMD process resulted in remarkable refinement of the microstructure. The as-deposited samples mainly consisted of $\mathrm{Nb}_{\mathrm{SS}}$, metastable $(\mathrm{NbTi})_{3} \mathrm{Si}$ and Ti-rich $\mathrm{Nb}_{\mathrm{SS}}$. With the increase in the laser power from 1000 to $2000 \mathrm{~W}$, the $\mathrm{Nb}_{\mathrm{SS}}$ morphology changed from discontinuous dendritic to near equiaxed, but the Ti-rich $\mathrm{Nb}_{\mathrm{SS}}$ phase tended to vanish. Furthermore, with the increase in the laser power, the microhardness of as-deposited samples increased from 822 to $951 \mathrm{HV}$, while the indentation fracture toughness was improved from 12.3 to $14.1 \mathrm{MPa} \mathrm{m}^{1 / 2}$. The corresponding mechanism is also discussed.
\end{abstract}

\section{KEY WORDS: Nb-Si-Ti alloys; Laser melting deposition; Microstructure; Mechanical properties; In situ} reaction

\section{Introduction}

$\mathrm{Nb}-\mathrm{Si}$-based alloys have shown high potential to replace Ni-based superalloys due to their high melting point $\left(>1750{ }^{\circ} \mathrm{C}\right)$ and low density $\left(6.6-7.2 \mathrm{~g} / \mathrm{cm}^{3}\right)$ as well as attractive specific mechanical properties at elevated temperatures [1-4]. Therefore the $\mathrm{Nb}-\mathrm{Si}$ alloys have become a new generation of ultra-high-temperature structural materials with potential service temperatures of $1200-1400{ }^{\circ} \mathrm{C}$ $[3,4]$. In general, the $\mathrm{Nb}-\mathrm{Si}$-based alloys are composed of $\mathrm{Nb}_{\mathrm{SS}}$ ( $\mathrm{Nb}$ solid solution) and silicide, in which the metallic

Available online at http://link.springer.com/journal/40195

Hua-Ping Xiong

xionghuaping69@sina.cn

1 3D Printing Research and Engineering Technology Center, Beijing Institute of Aeronautical Materials, Beijing 100095, China
$\mathrm{Nb}_{\text {ss }}$ offers room-temperature ductility while the reinforcing silicide supplies strength and creep resistance at high temperatures [5-7]. On the basis of many investigations, it has been recognized that the composition optimization $[8,9]$ and the processing innovations $[10,11]$ are very effective approaches for achieving a satisfactory balance between the properties of $\mathrm{Nb}-\mathrm{Si}$-based alloys.

Over the past few years, the influence of alloying elements such as $\mathrm{Ti}, \mathrm{Cr}, \mathrm{Al}, \mathrm{Hf}, \mathrm{Mo}$ and $\mathrm{W}$ on the microstructure, mechanical properties and oxidation behavior of $\mathrm{Nb}-$ Si-based alloys has been studied $[8,9,12,13]$. For example, it was found that Ti could decrease the brittle-ductile transition temperature (BDTT) $[8,13]$. In particular, it was reported that the fracture toughness of the as-cast $\mathrm{Nb}-16 \mathrm{Si}$ binary alloy was only $5.6 \mathrm{MPa} \mathrm{m}^{1 / 2}$, but it was increased remarkably to 11.3 $\mathrm{MPa} \mathrm{m}^{1 / 2}$ when 27 at.\% of Ti was added to the alloy [13]. In fact Ti was considered as one of the most effective toughening elements for the Nb-Si-based alloys. 
Moreover, the Ti addition can also cause the improvement of the high-temperature oxidation resistance [13]. However, the $\mathrm{Ti}$ addition concurrently reduces the eutectic temperature of reaction $\mathrm{L} \rightarrow \mathrm{Nb}_{\mathrm{SS}}+\mathrm{Nb}_{3} \mathrm{Si}$, i.e., the melting point of the alloys [14]. Furthermore, a high level of $\mathrm{Ti}$ would promote the formation of the $\mathrm{Ti}_{5} \mathrm{Si}_{3}$ phase, which is detrimental to the creep strength of the $\mathrm{Nb}-\mathrm{Si}$ based alloys [14]. For maintaining the melting temperature of $\mathrm{Nb}$-Si-based alloys above $1700{ }^{\circ} \mathrm{C}$ and meanwhile avoiding the $\mathrm{Ti}_{5} \mathrm{Si}_{3}$ formation, the addition of $\mathrm{Ti}$ to the $\mathrm{Nb}-$ Si-based alloys should be kept under 25 at.\% [14].

To date, several processing techniques including vacuum arc melting [8,9, 11, 15], induction melting [16], investment casting $[1,22]$, directional solidification (DS) $[6,15,17,18]$ and powder metallurgy $[10,19]$ have been successfully employed for the fabrication of $\mathrm{Nb}-\mathrm{Si}$-based alloys. However, the fabrication of components with complicated shape including hollow turbine blade for aero engine is still a great challenge. It should be noted that laser melting deposition (LMD), which is one kind of additive manufacturing technologies, could produce near net shape components with complex shapes and even with complex internal features $[20,21]$. Additionally, due to the rapid melting and solidification characteristics of the LMD manufacturing process, it is easy to achieve fine microstructures and to decrease the composition segregation of Nb-Si-based alloys, a fact that should be favorable to the improvement in the overall properties $[20,21]$. However, so far, only a few researches have been reported on the fabrication of $\mathrm{Nb}-\mathrm{Si}$-based alloys by additive manufacturing method [22-24]. For instance, the $\mathrm{Nb}-$ 22Si-26Ti-6Cr-3Hf-2Al alloy was deposited by laser directly forming from pre-alloyed powder, and the as-deposited alloy was mainly composed of $\mathrm{Nb}_{5} \mathrm{Si}_{3}$ and $\mathrm{Nb}_{\mathrm{SS}}$, in which the former phase has both large $(20-30 \mu \mathrm{m})$ particles and finely dispersed particles and the latter appears only as finely dispersed white particles [22]. Additionally, the $\mathrm{Nb}-18 \mathrm{Si}-24 \mathrm{Ti}-2 \mathrm{Cr}-2 \mathrm{Al}-2 \mathrm{Hf}$ alloy was built by selective laser melting (SLM) using pre-alloyed powder. The as-built alloy consisted of $\mathrm{Nb}_{\mathrm{sS}}, \alpha-\mathrm{Nb}_{5} \mathrm{Si}_{3}, \beta-\mathrm{Nb}_{5} \mathrm{Si}_{3}$ and $\mathrm{Nb}_{3} \mathrm{Si}$ phases [24]. However, so far, the studies concerning the LMD-processing of $\mathrm{Nb}-\mathrm{Si}$-based alloys are far insufficient.

In this study, an attempt was made to fabricate $\mathrm{Nb}-$ 17Si-23Ti ternary alloys from the starting materials of pure $\mathrm{Nb}, \mathrm{Si}$ and Ti powders by the in situ reaction LMD method. The effect of laser power on morphology, size and distribution of the constituent phases of the alloys was examined. Microhardness and indentation fracture toughness were evaluated as well, aiming at a better understanding of the influence of the microstructure on the mechanical properties.

\section{Experimental}

Powder particles of Nb (99.5 wt\% purity), Si (99.9 wt\%) and $\mathrm{Ti}(99.5 \mathrm{wt} \%)$ with near-equiaxed morphology and approximately $80 \mu \mathrm{m}$ in average size were chosen as raw materials, as shown in Fig. 1. A pure $\mathrm{Nb}$ plate with the dimension of about $100 \mathrm{~mm} \times 100 \mathrm{~mm} \times 10 \mathrm{~mm}$ was used as the laser deposition substrate.

Experiments of LMD were carried out using a $6 \mathrm{~kW}$ optical fiber laser processing system with six-axes numerical control working table and a synchronous powder feeder with two independent feeding units, which can simultaneously deliver two different kinds of powder particles with diverse feeding rates.

Because the melting points of the Nb-Si-based alloys are in excess of $1750{ }^{\circ} \mathrm{C}$ [1] and the melting point of pure $\mathrm{Nb}$ powder is up to $2468{ }^{\circ} \mathrm{C}$, high input energy should be applied in the LMD process. The preliminary experiments for fabrication of $\mathrm{Nb}-\mathrm{Si}$ alloys by LMD using $500 \mathrm{~W}$ showed that many unreacted raw powder particles still retained in the as-deposited sample, indicating that a laser power of $500 \mathrm{~W}$ was too low to prepare sound $\mathrm{Nb}-\mathrm{Si}$ based alloys by LMD. Therefore, the influence of the input energy was subsequently taken into account by comparing different laser powers of 1000 and $2000 \mathrm{~W}$. Based on the preliminary experiments, the following optimal parameters were obtained, as shown in Table 1. Argon was used as the shielding gas and also as powder carrier gas for protection of the molten pool. The oxygen content in the processing chamber was less than $100 \mathrm{ppm}$.

A dual powder feeding method, as schematically illustrated in Fig. 2a, was used to deposit the $\mathrm{Nb}-\mathrm{Si}-\mathrm{Ti}$ alloy samples. As shown in Fig. 2a, the laser beam and coaxial powder feeding nozzle move as an integral unit so that the powder particles from the two feeding units are delivered coaxially into the laser molten pool. The pure Si powder was delivered through one feeding unit and $\mathrm{Nb}+\mathrm{Ti}$ powder mixture with the composition of $\mathrm{Nb}-28$ at. $\%$ Ti was delivered by the other feeding unit. By adjusting the feeding rates of the two independent feeding units, the powder mass flow rates achieved were equal to $0.45 \mathrm{~g} / \mathrm{min}$ for the $\mathrm{Si}$ powder and $7 \mathrm{~g} / \mathrm{min}$ for the $\mathrm{Nb}+\mathrm{Ti}$ powder mixture (Table 1), respectively, so that the alloy with a target composition $\mathrm{Nb}-17 \mathrm{Si}-23 \mathrm{Ti}$ could be produced by LMD.

The laser scanning path is shown in Fig. 2b: the laser beam moved in a zigzag way with the hatch spacing of $0.5 \mathrm{~mm}$, and the area of $15 \mathrm{~mm} \times 15 \mathrm{~mm}$ approximately in size was deposited in the first layer, while in the subsequent layers the laser scanning path was turned with $90^{\circ}$ rotation layer by layer. The deposition thickness of each layer was about $0.5 \mathrm{~mm}$ when the $1000 \mathrm{~W}$ laser power was 

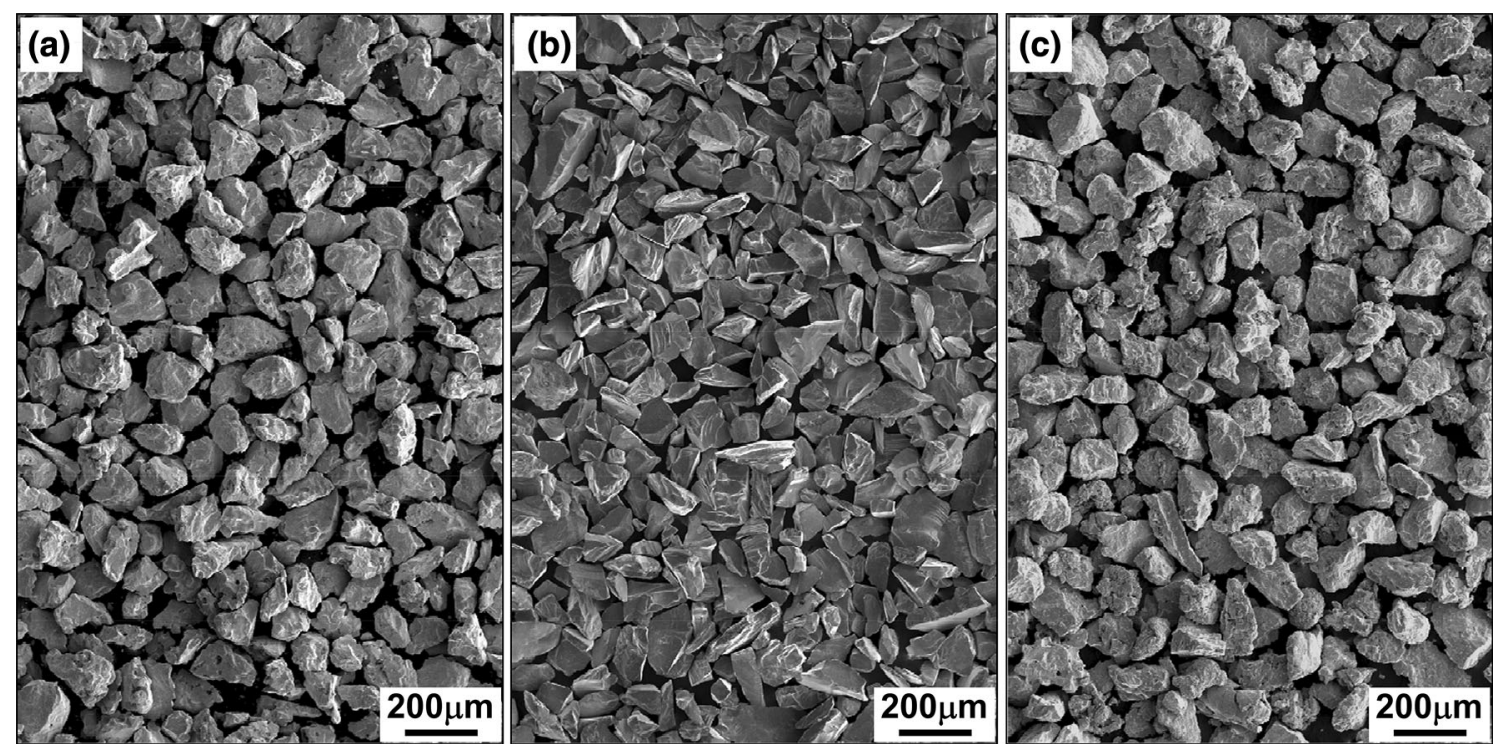

Fig. 1 SEI micrographs of the $\mathrm{Nb}$ powder $\mathbf{a}, \mathrm{Si}$ powder $\mathbf{b}$, Ti powder $\mathbf{c}$

Table 1 Fabrication parameters of LMD for the $\mathrm{Nb}-17 \mathrm{Si}-23 \mathrm{Ti}$ ternary alloys

\begin{tabular}{ll}
\hline Fabrication parameters & Values \\
\hline Laser spot diameter $(\mathrm{mm})$ & 0.8 \\
Scanning speed $(\mathrm{mm} \mathrm{min}$ & -1 \\
Hatch spacing $(\mathrm{mm})$ & 600 \\
Distance of substrate to laser focus point $(\mathrm{mm})$ & 0.5 \\
Si powder feed rate $\left(\mathrm{g} \mathrm{min}^{-1}\right)$ & 0 \\
$\mathrm{Nb}+$ Ti powder mixture feed rate $\left(\mathrm{g} \mathrm{min}^{-1}\right)$ & 0.45 \\
Laser power $(\mathrm{W})$ & 7 \\
\hline
\end{tabular}

used. For the case of $2000 \mathrm{~W}$, the thickness of the deposited layer was about $0.7 \mathrm{~mm}$. Consequently, after depositing 10 and 7 layers continuously, samples with a dimension of approximately $15 \mathrm{~mm} \times 15 \mathrm{~mm} \times 5 \mathrm{~mm}$ were achieved by $1000 \mathrm{~W}$ and $2000 \mathrm{~W}$ laser power, respectively.

The relative density of the as-deposited samples was determined by the immersion method in distilled water, based on Archimedes' principle. The contents of oxygen and nitrogen in the as-deposited alloys were determined using TCH600 (LECO) O, N and H analyzer. An X-ray diffraction analysis (XRD) was performed on the as-deposited samples to identify the phase constituents, using filtered $\mathrm{Cu} K \alpha$ radiation, $40 \mathrm{kV}$ and $300 \mathrm{~mA}$ (RIGAKU RINT 2500). The optical metallographs of the as-deposited samples were characterized by an optical microscope (Olympus BX51 M). Secondary electron images (SEI) of the powder morphologies, back-scattered electron (BSE) images of the microstructure of the as-deposited samples,

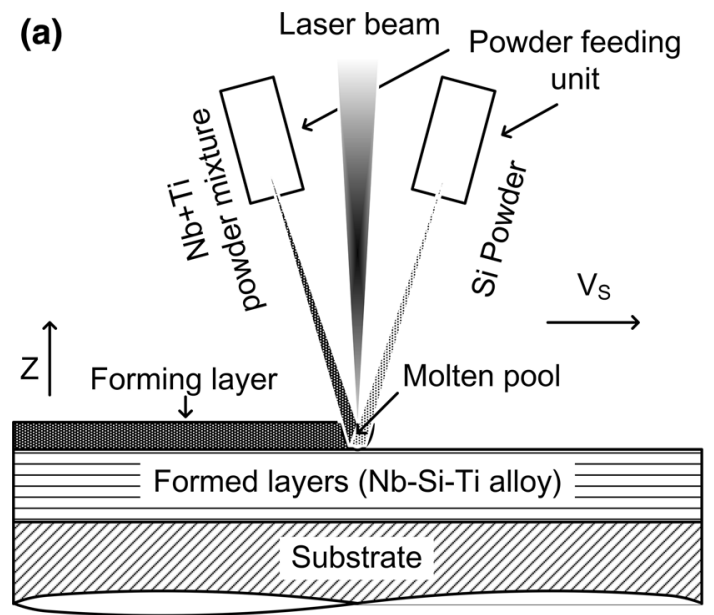

(b)

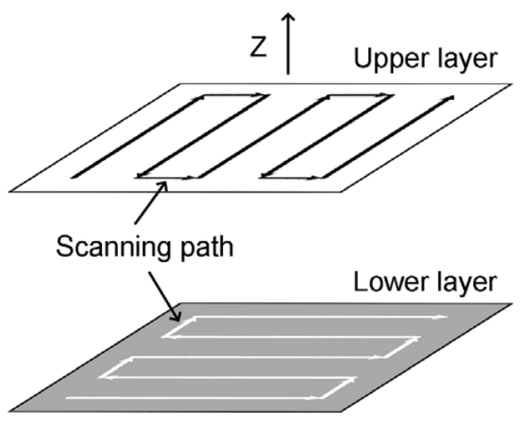

Fig. 2 Schematics of LMD with dual powder feeding method a, and scanning path of laser beam $\mathbf{b}$ 
and crack propagation path at the tips of hardness indentation were examined using a scanning electron microscope (SEM, FEI Quanta 200F). The chemical composition of the constituent phases was analyzed using an X-ray energydispersive spectrometer (EDS).

The Vickers microhardness (HV) was measured using an HXZ-1000 digital microhardness tester under a load of $9.8 \mathrm{~N}$ with a load-maintaining time of $15 \mathrm{~s}$. The average $\mathrm{HV}$ value was obtained from at least 5 tests on each sample. The samples were subjected to an indentation test with higher loads of $19.6 \mathrm{~N}$ with a load-maintaining time of $15 \mathrm{~s}$ to observe the cracks at the tips of the indentation and to determine the fracture toughness. The crack lengths at the edge of the indents were measured from the SEI micrographs. The indentation fracture toughness of the alloys was calculated using the following equation [25]:

$K_{i}=0.0123(E)^{0.4}(H)^{0.1}(P / I)^{0.5}$.

here $E$ is Young's modulus, $H$ refers to the hardness, $P$ is the load, and $I$ corresponds to the length of the crack from the tips of hardness indentation.

\section{Results}

\subsection{As-Deposited Nb-17Si-23Ti Alloy Samples}

Using the given processing parameters, the $\mathrm{Nb}-\mathrm{Si}-\mathrm{Ti}$ ternary alloy specimens without macro-defects were successfully fabricated by LMD with dual powder feeding method, as shown in Fig. 3. By comparing Fig. 3a and b, it can be seen that the specimen fabricated using $1000 \mathrm{~W}$ laser power exhibits better appearance and higher dimension precision than the specimen made using $2000 \mathrm{~W}$ laser power. As shown in Fig. $3 \mathrm{c}$ and d, only a few pores are observable in the as-deposited $\mathrm{Nb}-\mathrm{Si}$-Ti ternary alloys.

As seen in Table 2, the as-deposited samples have a relative density $(\rho)$ ranging from 98.3 to $99.4 \%$, which is comparable to that of the $\mathrm{Nb}-\mathrm{Si}$-based alloys prepared by reactive hot pressing sintering (RHPS) [26] and sparking plasma sintering (SPS) [19]. The analyzed compositions of the as-deposited alloys are very close to the target composition of $\mathrm{Nb}-17 \mathrm{Si}-23 \mathrm{Ti}$ : in particular, that of sample $\mathrm{A}$ is $\mathrm{Nb}-16.9 \mathrm{Si}-23.4 \mathrm{Ti}$, while that of sample $\mathrm{B}$ is $\mathrm{Nb}-16.2 \mathrm{Si}-$ 22.9Ti. However, in general there is a burning loss of the

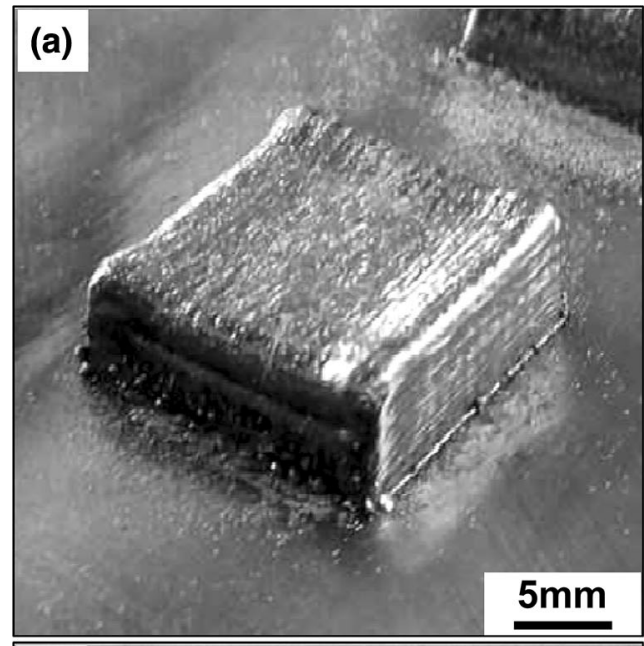

(c)

3

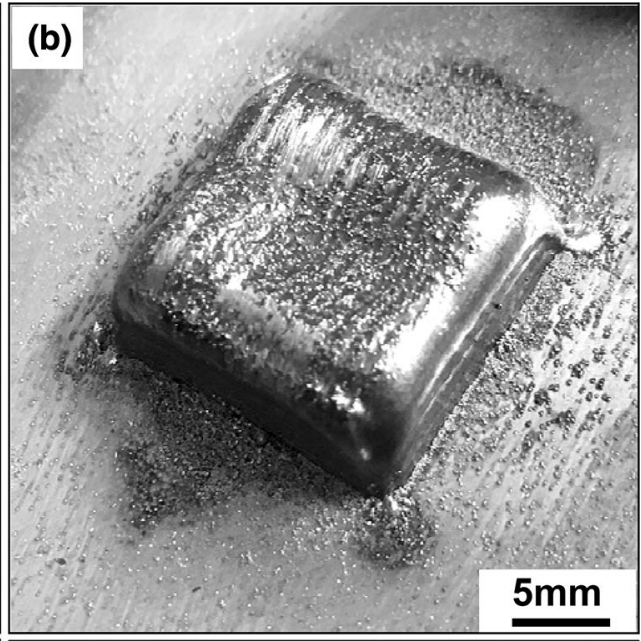

(d)

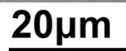

Fig. 3 Macro-photos and the cross-sectional optical metallographs of the as-deposited Nb-Si-Ti alloy specimens fabricated by LMD with $1000 \mathrm{~W}$ a-c, $2000 \mathrm{~W}$ b-d laser power, respectively 
Table 2 Relative density, $\mathrm{O}$ and $\mathrm{N}$ contents, and chemical composition of the as-deposited $\mathrm{Nb}-\mathrm{Si}-\mathrm{Ti}$ alloys

\begin{tabular}{lll}
\hline Samples & A $(1000 \mathrm{~W})$ & $\mathrm{B}(2000 \mathrm{~W})$ \\
\hline Relative density (\%) & 98.3 & 99.4 \\
O content (ppm) & 111 & 143 \\
$\mathrm{~N}$ content (ppm) & 35 & 68 \\
Composition (at.\%) & $\mathrm{Nb}-16.9 \mathrm{Si}-23.4 \mathrm{Ti}$ & $\mathrm{Nb}-16.2 \mathrm{Si}-22.9 \mathrm{Ti}$ \\
\hline
\end{tabular}

alloy elements especially for Si under the high energy of the laser beam. It is understandable that with the increase in the input energy, the burning loss should become higher: for example, for sample B ( $2000 \mathrm{~W})$ the Si concentration is 16.2 at.\%, a little lower than that for sample A $(1000 \mathrm{~W})$, but it seems that the composition changes of the two asdeposited alloys are still within an acceptable range. The $\mathrm{O}$ and $\mathrm{N}$ contents in the two as-deposited samples are less than $150 \mathrm{ppm}$ and $70 \mathrm{ppm}$, respectively. This reveals that the dense $\mathrm{Nb}-\mathrm{Si}-\mathrm{Ti}$ alloys with near target composition and with a rather low impurity content have been successfully achieved by LMD with the dual powder feeding method in the present study.

\subsection{Microstructure Characteristics}

Figure 4 shows the X-ray diffraction patterns of the $\mathrm{Nb}$ 17Si-23Ti samples deposited by 1000 and $2000 \mathrm{~W}$ laser power, respectively. The characteristic diffraction peaks of bcc $\mathrm{Nb}$ (JCPDS No. 34-0370) and tetragonal $\mathrm{Nb}_{3} \mathrm{Si}$ silicide (JCPDS No. 22-0763) were identified, while no other compounds were detected. This means that, regardless of the laser intensity, the as-deposited $\mathrm{Nb}-17 \mathrm{Si}-23 \mathrm{Ti}$ samples

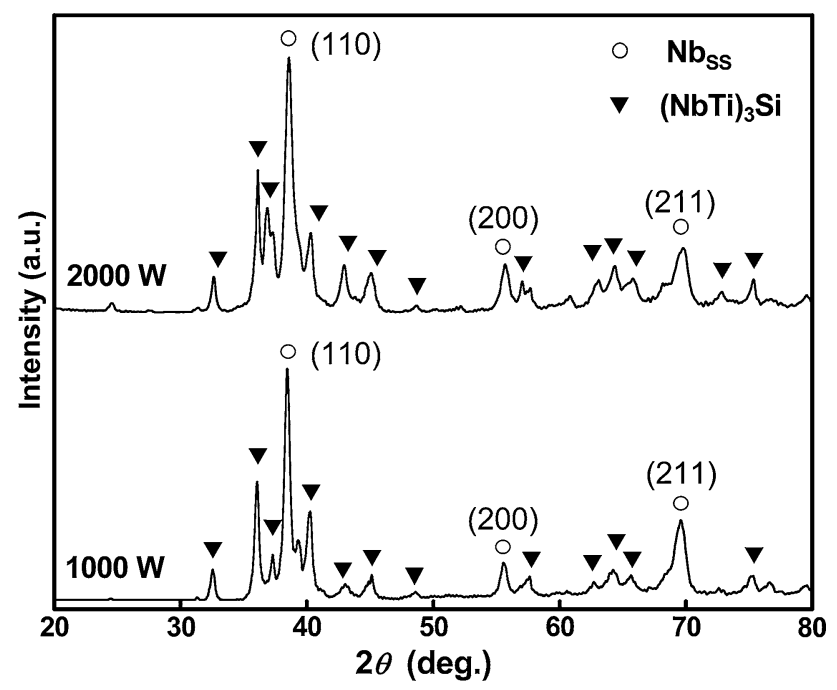

Fig. $4 \mathrm{X}$-ray diffraction patterns for the as-deposited $\mathrm{Nb}-17 \mathrm{Si}-23 \mathrm{Ti}$ samples fabricated by LMD using 1000 and $2000 \mathrm{~W}$ laser power, respectively are mainly composed of the same two phases: $\mathrm{Nb}_{\mathrm{SS}}$ and $\mathrm{Nb}_{3} \mathrm{Si}$. According to the $\mathrm{Nb}-\mathrm{Si}-\mathrm{Ti}$ ternary diagram [14], the $\mathrm{Nb}_{3} \mathrm{Si}$ phase is metastable at room temperature. However, generally, the metastable $\mathrm{Nb}_{3} \mathrm{Si}$ phase existed in most $\mathrm{Nb}-\mathrm{Si}$ binary [6] or $\mathrm{Nb}-\mathrm{Si}-\mathrm{Ti}$ ternary [6] alloys fabricated by cast methods owing to the incomplete or sluggish eutectoid reaction [27]. Due to the rapid solidification characteristics of the LMD process and the stabilizing effect of $\mathrm{Ti}$ on $\mathrm{Nb}_{3} \mathrm{Si}$ at lower temperatures [13], the eutectoid decomposition reaction, $\mathrm{Nb}_{3} \mathrm{Si} \rightarrow \mathrm{Nb}+\mathrm{Nb}_{5} \mathrm{Si}_{3}$, was completely suppressed, and thus $\mathrm{Nb}_{3} \mathrm{Si}$ was retained in the $\mathrm{Nb}-17 \mathrm{Si}-23 \mathrm{Ti}$ samples prepared by LMD.

The back-scattered electron (BSE) images of the microstructure of the samples A and B are shown in Fig. 5, where three phases are observed with clear contrasts of bright, gray and dark phases. The EDS analysis results are given in Table 3. By combining the XRD (Fig. 4) and EDS (Table 3) results, it is confirmed that in the BSE images (Fig. 5) the bright and gray phases are $\mathrm{Nb}_{\mathrm{SS}}$ and $(\mathrm{NbTi})_{3} \mathrm{Si}$, respectively. Obviously they are the main constituents in the as-deposited alloy. In addition, the dark phase particles existing within the interdendrites are determined to be $\mathrm{Ti}-$ rich $\mathrm{Nb}_{\mathrm{SS}}$ by EDS analysis (Table 3; Fig. 5b).

It can be seen from Fig. $5 \mathrm{a}$ and $\mathrm{b}$ that in sample $\mathrm{A}$ fabricated by $1000 \mathrm{~W}$ laser power, the constituent phase $\mathrm{Nb}_{\mathrm{SS}}$ is characterized by a discontinuous dendritic structure, with average size of about $3 \mu \mathrm{m}$ in length and less than $1 \mu \mathrm{m}$ in width. The $(\mathrm{NbTi})_{3} \mathrm{Si}$ phase presents near quadrilateral shape of about $2 \mu \mathrm{m}$ in average size. Meanwhile, some Ti-rich $\mathrm{Nb}_{\mathrm{Ss}}$ particles are found to exist between the dendritic arms. It is deduced that they should be formed from the lower-melting-point Ti solidified at the end of the solidification process and enriched in the interdendritic regions. The Ti-rich $\mathrm{Nb}_{\mathrm{SS}}$ phase existing in the $\mathrm{Nb}-\mathrm{Si}$-Ti-based alloys was reported in other references $[28,29]$ as well. It can also be found in Fig. 5a and $b$ that most of the interfaces between $\mathrm{Nb}_{\mathrm{SS}}$ and $(\mathrm{NbTi})_{3} \mathrm{Si}$ are almost straight in the $\mathrm{Nb}-17 \mathrm{Si}-23 \mathrm{Ti}$ alloy fabricated by $1000 \mathrm{~W}$ laser power, which might be attributed to the growth of the intermetallic $(\mathrm{NbTi})_{3} \mathrm{Si}$ phase in a typical small-faceted structure in this case.

The BSE images of sample B in Fig. $5 \mathrm{c}$ and d show that the microstructure is refined and becomes more homogeneous by increasing the laser power from 1000 to $2000 \mathrm{~W}$. The $(\mathrm{NbTi})_{3} \mathrm{Si}$ distributed continuously as matrix phase and $\mathrm{Nb}_{\text {ss }}$ became finer, with an average size $1 \mu \mathrm{m}$ or less. Interestingly, some of the extremely fine $(\mathrm{NbTi})_{3} \mathrm{Si}$ particles of about $300 \mathrm{~nm}$ in average size were wrapped by the $\mathrm{Nb}_{\text {ss }}$. Meanwhile, very small amounts of Ti-rich $\mathrm{Nb}_{\mathrm{SS}}$ particles (dark contrast, see the enlarged image in Fig. 5d) existed at the $\mathrm{Nb}_{\mathrm{SS}} /(\mathrm{NbTi})_{3} \mathrm{Si}$ interface. That is, the Ti-rich $\mathrm{Nb}_{\text {ss }}$ particles tended to vanish when the laser power was increased to $2000 \mathrm{~W}$. 

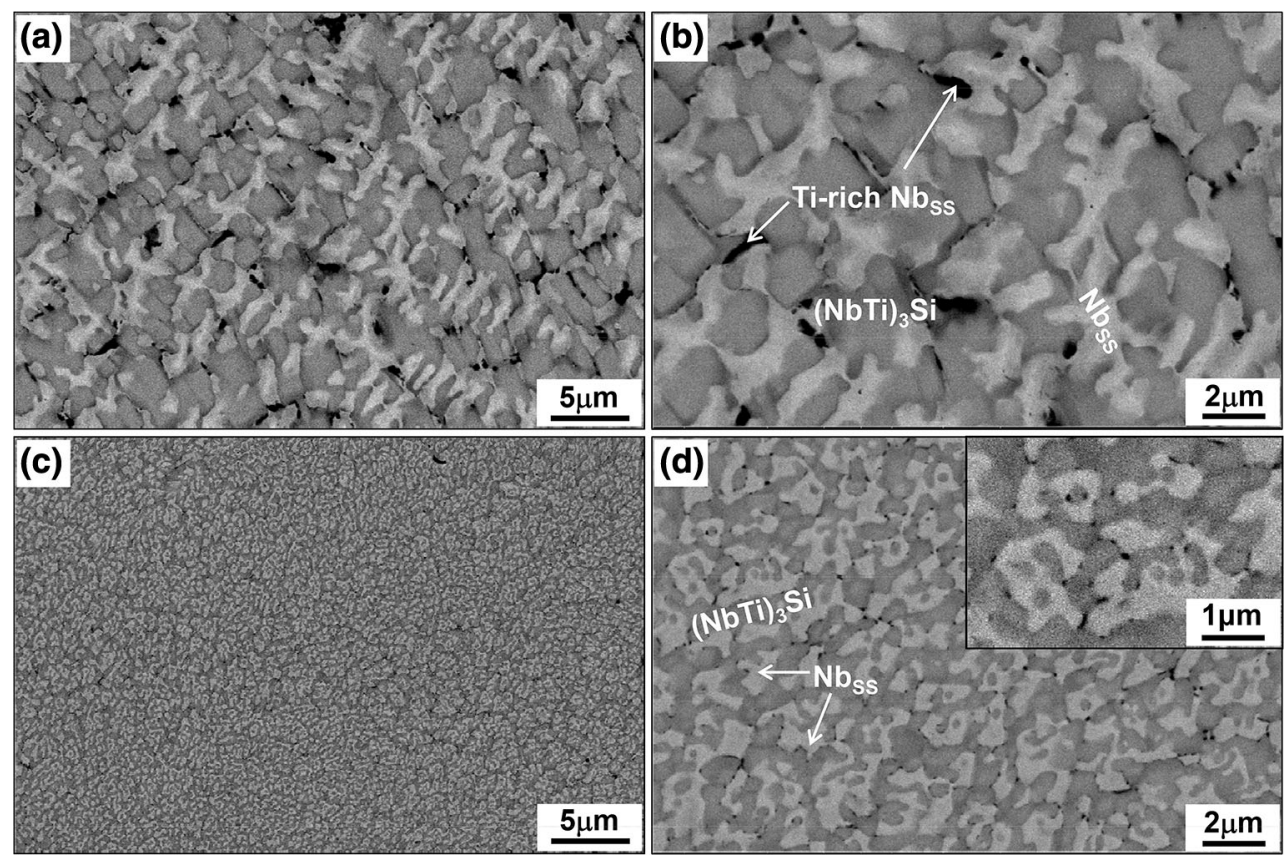

Fig. 5 BSE images of the as-deposited $\mathrm{Nb}-17 \mathrm{Si}-23 \mathrm{Ti}$ alloys fabricated by LMD with the laser power of $1000 \mathrm{~W}$ a, b, $2000 \mathrm{~W}$ c, d, respectively. Insert in $\mathbf{d}$ is an enlarged image

Table 3 Elemental atomic concentration for the constituent phases of as-deposited $\mathrm{Nb}-17 \mathrm{Si}-23 \mathrm{Ti}$ alloys

\begin{tabular}{|c|c|c|c|c|c|}
\hline Samples & Phase contrast & Si (at.\%) & $\mathrm{Nb}$ (at.\%) & Ti (at.\%) & Deduced phase \\
\hline \multirow[t]{3}{*}{ A $(1000 \mathrm{~W})$} & Bright & 3.01 & 67.32 & 29.67 & $\mathrm{Nb}_{\mathrm{SS}}$ \\
\hline & Gray & 27.22 & 58.87 & 13.91 & $(\mathrm{NbTi})_{3} \mathrm{Si}$ \\
\hline & Dark & 3.25 & 50.93 & 45.82 & Ti-rich $\mathrm{Nb}_{\mathrm{SS}}$ \\
\hline \multirow[t]{2}{*}{ B $(2000 \mathrm{~W})$} & Bright & 4.45 & 61.26 & 34.29 & $\mathrm{Nb}_{\mathrm{SS}}$ \\
\hline & Gray & 23.86 & 57.80 & 18.34 & $(\mathrm{NbTi})_{3} \mathrm{Si}$ \\
\hline
\end{tabular}

It is noteworthy that with the increase in the laser power, the interface between $\mathrm{Nb}_{\mathrm{SS}}$ and $(\mathrm{NbTi})_{3} \mathrm{Si}$ is no longer straight but becomes more smooth, indicating that the $(\mathrm{NbTi})_{3} \mathrm{Si}$ shows non-faceted solidification characteristics under this condition. According to the Jackson-Hunt theory [30], the intermetallic $\mathrm{Nb}_{3} \mathrm{Si}$ is a faceted phase, therefore the angular edges of $\mathrm{Nb}_{3} \mathrm{Si}$ phase are observable in the as-deposited sample A. However, with the laser power increasing, the thermal gradient becomes steeper (as discussed later in this paper) and the faceted $\mathrm{Nb}_{3} \mathrm{Si}$ particles may show non-faceted characteristic to some extent, which has been demonstrated in other researches as well $[31,32]$.

\subsection{Mechanical Properties}

Microhardness (HV) and indentation fracture toughness $\left(K_{i}\right)$ were measured to compare the mechanical properties of the as-deposited samples prepared by LMD using different laser powers, and the results are summarized in

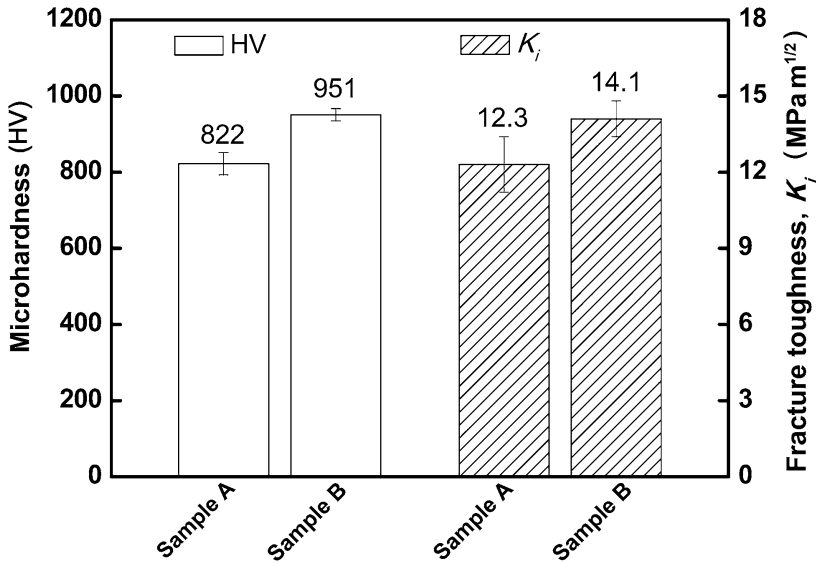

Fig. 6 Vickers hardness and indentation fracture toughness of asdeposited $\mathrm{Nb}-17 \mathrm{Si}-23 \mathrm{Ti}$ samples

Fig. 6. The average HV of the sample A for $1000 \mathrm{~W}$ laser power is lower, $822 \mathrm{HV}$, and the microhardness of the sample B for $2000 \mathrm{~W}$ is enhanced by about $15 \%$, reaching 
$951 \mathrm{HV}$. The main reason for the increase in microhardness might lie on the microstructure refinement (see Fig. 5). As described by the Hall-Petch equation [33], small phase particles typically result in greater strengthening effect. Metals with finer grains are harder and stronger than those with coarse grains, since the former have a greater total grain boundary area to impede dislocation motion. In addition, the solid solution strengthening effect in $\mathrm{Nb}_{\mathrm{SS}}$ was improved to some extent by the increase in laser power as well. For instance, as shown in Table 2, the concentrations of $\mathrm{Si}$ and $\mathrm{Ti}$ in the $\mathrm{Nb}_{\mathrm{SS}}$ of sample $\mathrm{A}(1000 \mathrm{~W})$ are 3.01 and 29.67 at.\%, respectively, whereas they were increased up to 4.45 and 34.29 at. $\%$ in the $\mathrm{Nb}_{\mathrm{SS}}$ of sample B $(2000 \mathrm{~W})$.

As seen in Fig. 6, the average indentation fracture toughness $\left(K_{i}\right)$ values are affected by the laser power of LMD, even though both samples have approximately the same composition of $\mathrm{Nb}-17 \mathrm{Si}-23 \mathrm{Ti}$. An increase in the laser power has a positive influence on the fracture toughness since the value of $K_{i}$ increases from 12.3 to $14.1 \mathrm{MPa} \mathrm{m}^{1 / 2}$ with the increase in the laser power from 1000 to $2000 \mathrm{~W}$.

\section{Discussion}

\subsection{Evolution Mechanism of the Microstructure}

In the conventional cast $\mathrm{Nb}-\mathrm{Si}$-based alloys, the coarsened microstructure presented the primary phase size up to tens or hundreds of microns due to the slow solidification rate $[7,8,15,16]$. However, in this study, the $\mathrm{Nb}-17 \mathrm{Si}-23 \mathrm{Ti}$ alloys with rather fine microstructure of a few microns were achieved, signifying that the microstructure has been refined approximately by 1-2 orders of magnitude through LMD. The LMD process is a kind of additive manufacture technology based on the forming principle of scatter accumulation [20]. The metal powder particles were fully melted by the high-energy laser beam and solidified rapidly as the laser beam moved away, and then the as-deposited parts were built by overlapping the multi-tracks and multilayers. As we know, the thermal gradient, $G$, and the solidification velocity, $V$, are the most important parameters which govern the solidification microstructure of a given alloy [34]. On the basis of the solidification theory, the fineness of microstructure and the $G$ and $V$ values in the solidification process obey the following approximate expression [35]:

$\lambda \propto G^{-a} V^{-b}$.

where $\lambda$ is the dendritic spacing, while $a$ and $b$ are materialdependent constants.

During the LMD process, the solidification velocity $V$ is related to the scanning velocity and the angle between the direction of the moving laser source and the growth direction. The thermal gradient $G$ is given by the temperature field generated by higher intensity heat source of the laser, while $G$ in the molten pool has been reported to be as high as $10^{6}{ }^{\circ} \mathrm{C} \mathrm{m}^{-1}$ [34]. However, during the process of traditional directional solidification, the thermal gradient $G$ of the liquid-solid interface in the steady state is of the order of $10^{4}{ }^{\circ} \mathrm{C} \mathrm{m}^{-1}$ [6]. According to the expression (2), due to the higher value of $G$, the microstructure of $\mathrm{Nb}-$ 17Si-23Ti alloys fabricated by LMD has been refined. In addition, the $\mathrm{Nb}, \mathrm{Si}$ and $\mathrm{Ti}$ powder particles were used as starting materials in this study. The laser-induced in situ reaction of the powder mixture could also refine the microstructure of the $\mathrm{Nb}-\mathrm{Si}-\mathrm{Ti}$ alloy [36]. Therefore, the remarkably refined $\mathrm{Nb}-17 \mathrm{Si}-23 \mathrm{Ti}$ alloys were achieved by LMD with dual powder feeding method.

Comparing the microstructure of the samples prepared using a laser power of $1000 \mathrm{~W}$ (Fig. 5a, b) and $2000 \mathrm{~W}$ (Fig. 5c, d), it is clear that the higher laser power is beneficial to the microstructure refinement. In the process of laser scanning line by line, the input energy can be used to define the line energy density $\eta(\mathrm{J} / \mathrm{m})$ as $\eta=P / v$, where the $P$ is laser power and $v$ is scanning rate. According to this equation, in the case of constant scanning speed, the increase in the laser power can enhance the energy density and then raise the temperature of the $\mathrm{Nb}-\mathrm{Si}-\mathrm{Ti}$ molten pool, implying that the thermal gradient $G$ would become steeper with the laser power increasing. The previous results of numerical simulation showed that the thermal gradient along the depth direction of the molten pool increased considerably from 10.6 to $21.7^{\circ} \mathrm{C} / \mu \mathrm{m}$ as the laser power was increased from 150 to $300 \mathrm{~W}$ during the additive manufacturing of AlSi10 Mg alloys by selective laser melting (SLM) [37]. Once again, according to the expression (2), larger $G$ values are helpful for the microstructure refinement, and hence, finer microstructures would be achieved by higher laser powers. In addition, the segregation could be also restrained by the steeper thermal gradient [38], so that the Ti-rich $\mathrm{Nb}_{\mathrm{SS}}$ nearly disappeared with the increase in the laser power.

Figure 5 shows that the increase in the laser power not only decreased the size of $\mathrm{Nb}_{\mathrm{SS}}$ but also changed its morphology. The dendritic morphology degraded when the laser power increased. As known, the mode of solidification is determined by the ratio between the thermal gradient $(G)$ over the solidification velocity $(V), G / V$, which controls the stability of the solidification front [35, 39]. For a given alloy, the higher the value of $G / V$ is, the smaller the undercooling tendency at the front of the liquid-solid interface is, so that the microstructure is changed from dendritic to cellular and then to planar. Therefore, the morphology of $\mathrm{Nb}_{\mathrm{SS}}$ in samples $\mathrm{A}$ and $\mathrm{B}$ changed from dendritic to near-equiaxed (see Fig. 5). Additionally, 

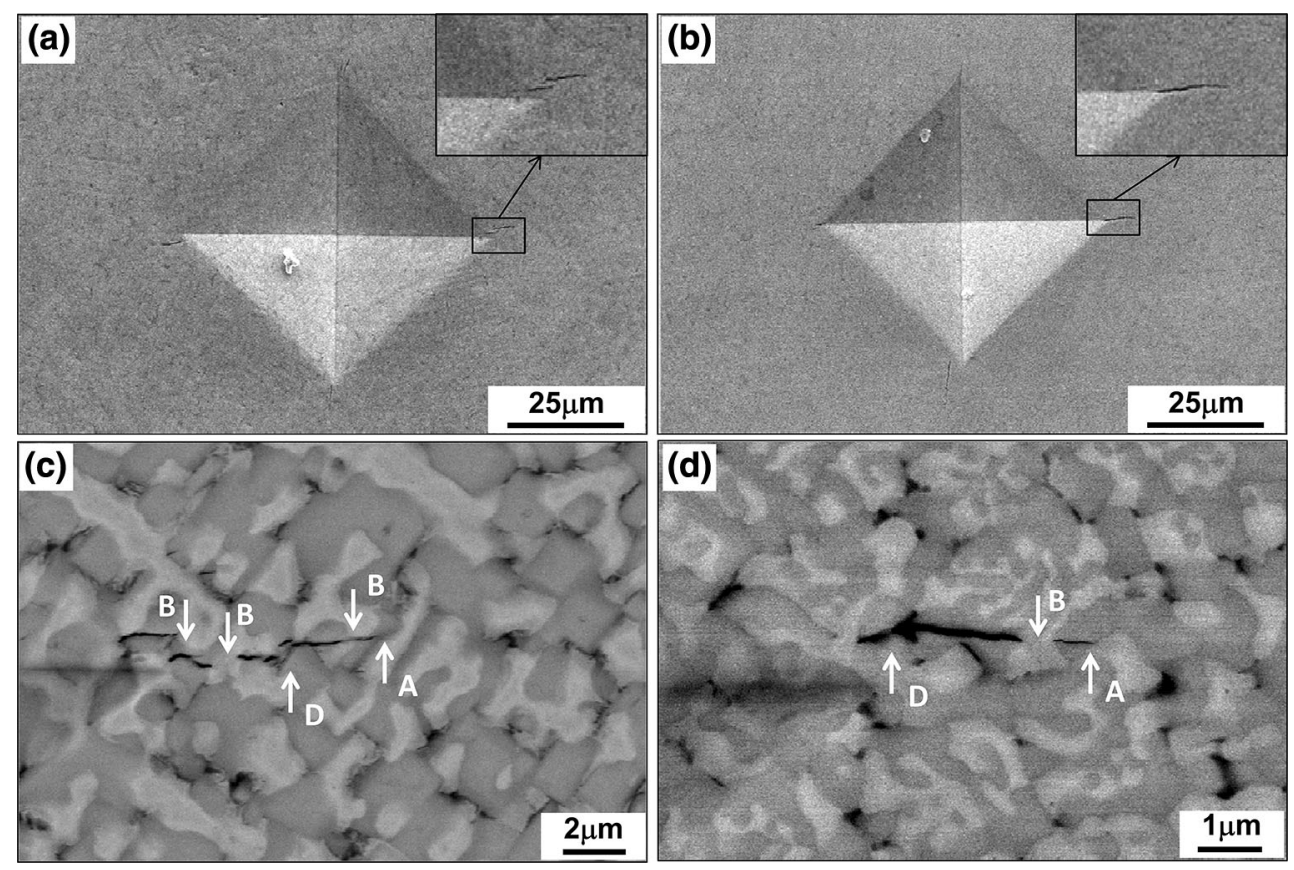

Fig. 7 BSE images of the hardness indentation $\mathbf{a}, \mathbf{b}$, and the cracks at the tips of hardness indentation $\mathbf{c}, \mathbf{d}$ on the as-deposited samples fabricated by LMD with $1000 \mathrm{~W}$ a-c, $2000 \mathrm{~W}$ b-d laser power, respectively

during the LMD process, the strength of the Marangoni flow in the Nb-Si-Ti molten pool is increased by higher thermal gradient and molten pool temperature [40] and this would accelerate the atom diffusion rate and inhibit the dendrite growth as well. Based on the above factors, the dendritic morphology tended to disappear with the increase in laser power.

\subsection{Toughening Mechanism of the Laser-Deposited Nb-17Si-23Ti Alloys}

To understand the influence of the constituent phases on the fracture toughness of the $\mathrm{Nb}-17 \mathrm{Si}-23 \mathrm{Ti}$ alloys developed by LMD, the crack paths at the tips of hardness indentation were observed, as shown in Fig. 7. The $\mathrm{Nb}_{\mathrm{SS}}$ and $(\mathrm{NbTi})_{3} \mathrm{Si}$ phases show different behaviors during the penetration of the hardness indenter, indirectly indicating their influence on the bulk toughness. In most cases when the microcracks meet the $\mathrm{Nb}_{\mathrm{SS}}$ phase, they bridge (arrows B in Fig. 7), or deflect (arrows D in Fig. 7), or are arrested by the $\mathrm{Nb}_{\mathrm{SS}}$ phase (arrows A in Fig. 7). Whereas, for the ( $\mathrm{NbTi})_{3} \mathrm{Si}$, the cracks generally propagate directly throughout it. This suggests that the $\mathrm{Nb}_{\mathrm{SS}}$ phase plays a key role in preventing the crack propagation in the as-deposited $\mathrm{Nb}-17 \mathrm{Si}-23 \mathrm{Ti}$ alloys. However, the $(\mathrm{NbTi})_{3} \mathrm{Si}$ cannot effectively stop the crack propagation, so that the fracture toughness of monophase $\mathrm{Nb}_{3} \mathrm{Si}$ is commonly less than $3 \mathrm{MPa}{ }^{1 / 2}$ [41].

As shown in Fig. 6, the sample B fabricated using higher laser power exhibits higher $K_{i}$ than the sample A (14.1 vs. 12.3 $\mathrm{MPa} \mathrm{m}^{1 / 2}$ ). This result should be attributed to the following reasons. For the microstructure of sample B, as shown in Fig. 5 d, some of the $(\mathrm{NbTi})_{3} \mathrm{Si}$ particles are surrounded by the ductile $\mathrm{Nb}_{\mathrm{SS}}$, which is beneficial to the fracture toughness. Additionally, previous studies have shown that the Nb-Si-based alloys with extremely refined $\mathrm{Nb}$ grains may lead to a transition of the failure mode of $\mathrm{Nb}_{\mathrm{SS}}$ from cleavage to dimple/tear [19]. Therefore, the finer microstructure of the as-deposited sample B should have contributed to the improvement of $K_{i}$ to some extent. Furthermore, the content of the Ti dissolved in $\mathrm{Nb}_{\mathrm{SS}}$ of sample B is higher than that of sample A (34.29 vs. 29.67 at.\%, see Table 2). Theoretical calculations have demonstrated that $\mathrm{Ti}$ can impart fracture toughness resistance in the $\mathrm{Nb}_{\mathrm{SS}}$ and $\mathrm{Nb}$ based silicides by altering the crystal structure to promote slip by partial dislocations, reducing the Peierls-Nabarro barrier energy (energy for starting the slip of dislocation) and increasing the $\gamma_{\mathrm{s}} / U_{\mathrm{P}-\mathrm{N}}$ ratio, where $\gamma_{\mathrm{s}}$ is the cleavage surface energy and $U_{\mathrm{P}-\mathrm{N}}$ is the $\mathrm{P}-\mathrm{N}$ barrier energy [8]. Hence, with higher dissolved $\mathrm{Ti}$ content, the $\mathrm{Nb}_{\mathrm{SS}}$ in the sample B was considerably toughened, which undoubtedly led to a lower propensity for cleavage fracture and a higher fracture resistance of $\mathrm{Nb}$ than those of the sample $\mathrm{A}$.

\section{Conclusions}

The fabrication of dense $\mathrm{Nb}-17 \mathrm{Si}-23 \mathrm{Ti}$ alloys was successfully obtained by in situ reaction LMD. The microstructure characteristics and mechanical properties of the alloys were studied. The conclusions may be summarized as follows: 
1. The relative density of the as-deposited $\mathrm{Nb}-17 \mathrm{Si}-23 \mathrm{Ti}$ alloys was not less than $98.3 \%$, and the alloys were mainly composed of $\mathrm{Nb}_{\mathrm{SS}}$, metastable ( $\left.\mathrm{NbTi}\right)_{3} \mathrm{Si}$ and Ti-rich $\mathrm{Nb}_{\mathrm{SS}}$ regardless of the input laser intensity, even though the Ti-rich $\mathrm{Nb}_{\mathrm{SS}}$ tended to vanish with the increase in the laser power from 1000 to $2000 \mathrm{~W}$.

2. Nb-17Si-23Ti alloy samples with a remarkably refined microstructure were obtained by LMD. With the increase in the laser power, the average size of the $\mathrm{Nb}_{\text {SS }}$ phase particles was refined from about $3 \mu \mathrm{m}$ to less than $1 \mu \mathrm{m}$, while the $\mathrm{Nb}_{\mathrm{SS}}$ morphology changed from discontinuous dendritic to near equiaxed.

3. $\mathrm{Nb}_{\mathrm{SS}}$ contributed to the fracture toughness through crack bridging, deflection and stopping in the asdeposited alloys. Furthermore, in the as-deposited alloy fabricated using higher laser power of $2000 \mathrm{~W}$, the microhardness and indentation fracture toughness reached values of $951 \mathrm{HV}$ and $14.1 \mathrm{MPa} \mathrm{m}^{1 / 2}$, respectively. Three factors should have contributed to the improved fracture toughness of this alloy as compared with that produced with the laser power of $1000 \mathrm{~W}$ : the structure of ductile $\mathrm{Nb}_{\mathrm{SS}}$ wrapping the brittle $\mathrm{Nb}_{3} \mathrm{Si}$ particles, a more homogeneous and finer microstructure and a stronger toughening effect by a higher solid solubility of $\mathrm{Ti}$ in $\mathrm{Nb}_{\mathrm{SS}}$.

Acknowledgement The authors are grateful to the support by the National Natural Science Foundation of China (Grant No. 51605456).

\section{References}

[1] B.P. Bewlay, M.R. Jackson, P.R. Subramanian, J.C. Zhao, Metall. Mater. Trans. A 34, 2043 (2003)

[2] M.R. Jackson, B.P. Bewlay, R.G. Rowe, D.W. Skelly, H.A. Lipsitt, JOM 48, 39 (1996)

[3] C.M. Liu, H.M. Wang, S.Q. Zhang, H.B. Tang, A.L. Zhang, J. Alloys Compd. 583, 162 (2014)

[4] J.C. Zhao, J.H. Westbrook, MRS Bull. 28, 622 (2003)

[5] W.Y. Kim, H. Tanaka, A. Kasama, S. Hanada, Intermetallics 9, 827 (2001)

[6] N. Sekido, Y. Kimura, S. Miura, F. Wei, Y. Mishima, J. Alloys Compd. 425, 223 (2006)

[7] T. Fei, Y. Yu, C. Zhou, J. Sha, Mater. Des. 116, 92 (2017)

[8] K.S. Chan, Mater. Sci. Eng., A 329, 513 (2002)

[9] J. Sha, C. Yang, J. Liu, Scr. Mater. 62, 859 (2010)
[10] T. Murakami, S. Sasaki, K. Ichikawa, A. Kitahara, Intermetallics 9, $621(2001)$

[11] Y. Wang, X. Guo, Y. Qiao, Mater. Des. 116, 461 (2017)

[12] K. Zelenitsas, P. Tsakiropoulos, Mater. Sci. Eng. A 416, 269 (2006)

[13] J. Geng, P. Tsakiropoulos, G. Shao, Mater. Sci. Eng. A 441, 26 (2006)

[14] B.P. Bewlay, M.R. Jackson, R.R. Bishop, J. Phase Equilib. 19, 577 (1998)

[15] J. Sha, H. Hirai, H. Ueno, T. Tabaru, A. Kitahara, S. Hanada, Metall. Mater. Trans. A 34, 85 (2003)

[16] X. Li, H. Chen, J. Sha, H. Zhang, Mater. Sci. Eng., A 527, 6140 (2010)

[17] B.P. Bewlay, M.R. Jackson, J.C. Zhao, P.R. Subramanian, M.G. Mendiratta, J.J. Lewandowski, MRS Bull. 28, 646 (2003)

[18] B. Guo, X. Guo, Mater. Sci. Eng. A 617, 39 (2014)

[19] W. Liu, J. Sha, Mater. Des. 111, 301 (2016)

[20] E.M. Lawrence, J. Mater. Sci. Technol. 32, 987 (2016)

[21] G.P. Dinda, A.K. Dasgupta, J. Mazumder, Mater. Sci. Eng. A 509, 98 (2009)

[22] R. Dicks, F. Wang, X. Wu, J. Mater. Process. Technol. 209, 1752 (2009)

[23] R.R. Dehoff, P.M. Sarosi, P.C. Collins, L.F. Hamish, J.M. Michael, MRS Online Proc. Libr. 753, 2 (2011)

[24] Y. Guo, L. Jia, S. Sun, B. Kong, J. Liu, H. Zhang, Mater. Des. 109, 37 (2016)

[25] A.G. Evans, E.A. Charles, J. Am. Ceram. Soc. 59, 371 (1976)

[26] J.L. Yu, K.F. Zhang, Scr. Mater. 59, 714 (2008)

[27] M.G. Mendiratta, J.J. Lewandowski, D.M. Dimiduk, Metall. Trans. A 22, 1573 (1991)

[28] K. Zelenitsas, P. Tsakiropoulos, Intermetallics 13, 1079 (2005)

[29] L. Su, L. Jia, Y. Feng, H. Zhang, S. Yuan, H. Zhang, Mater. Sci. Eng. A 560, 672 (2013)

[30] K.A. Jackson, J.D. Hunt, A.I.M.E. Met, Soc. Trans. 236, 1129 (1966)

[31] C.T. Lynch, J.P. Kershaw, (CRC Press, Boca Raton 1972), p. 121

[32] Y. Li, S. Miura, K. Ohsasa, C. Ma, H. Zhang, Intermetallics 19, 460 (2011)

[33] N. Hansen, Scr. Mater. 51, 801 (2004)

[34] L. Wang, N. Wang, W.J. Yao, Y.P. Zheng, Acta Mater. 88, 283 (2015)

[35] M.C. Flemings, Metall. Trans. A 5, 2121 (1974)

[36] H. Attar, K.G. Prashanth, L.C. Zhang, M. Calin, I.V. Okulov, S. Scudino, C. Yang, J. Eckert, J. Mater. Sci. Technol. 31, 1001 (2015)

[37] Y. Li, D. GU, Mater. Des. 63, 856 (2014)

[38] H. Liao, W. Huang, Q. Wang, F. Jia, J. Mater. Sci. Technol. 30, $146(2014)$

[39] Y.J. Liang, X. Cheng, H.M. Wang, Acta Mater. 118, 17 (2016)

[40] K. Arafune, A. Hirata, J. Cryst. Growth 197, 811 (1999)

[41] E. Guo, S.S. Singh, C. Mayer, X. Meng, Y. Xu, L. Luo, M. Wang, N. Chawla, J. Alloys Compd. 704, 89 (2017) 